\title{
Gaming of Strategy--Strategic Realignment of Chinese Dairy Industry
}

\author{
Liqin Shan \& Jinzhao An \\ School of Management, Northwest University for Nationalities, Lanzhou, 730030, China \\ Tel: 86-931-833-1169 E-mail: anjinzhao6@163.com
}

\begin{abstract}
Over the past ten-odd years, the dizzying prosperity and rapid development achieved in Chinese Dairy Industrial $t$ actually covered up a fundamental defect concerning the strategy, which eventually led to the "Melamine Event". Today, the troubled waters has been poured oil on, but it still needs time to be recovered. China's Dairy Industry, which suffered heavy losses and casualties, is about to seek for a transformation and will have to help himself out of the crisis. This paper will apply the game theory of "Prisoner's Dilemma" case to reflect the strategic defects appeared in the early dairy industrial development, with the combination of the new changes in the dairy industrial development environment after "Melamine Event", it also points out that the key to revitalize the domestic dairy enterprises is to put the emphasis on the nature of the dairy industry itself, to return to consumers standard, to try to establish the undifferentiated marketing strategy and differentiated marketing strategy system.
\end{abstract}

Keywords: Melamine, Prisoner's Dilemma, Strategic Realignment, Dairy Industry

After rapid growth for a decade, Chinese dairy industry has taken a hit in melamine storm. The wheels of history will never stop, the disgrace has passed away. It's necessary to learn from the mistakes for re-emergence in the murky market environment. Research on the sound development pattern is important for the Chinese diary industry and is of strategic importance.

\section{Melamine incident-Chinese diary industry has encountered prisoner's dilemma}

Study on the melamine incident is essential for the strategic development of Chinese diary industry. Superficially, a collective moral hazard, its essence is the result of a long-term contradiction accumulation during the rapid development stage.

The Chinese diary industry has developed with annual growth rate of $30 \%$ before with the continuous raise of market demand and capital input. The diary industry has superiority over promoting the peasant income, employment, local public finance, and lower barrier to entry. Its development is influenced by the general market discipline and especially local government. The Chinese diary industry developed too quickly for its unique industry characteristic, and landed in deep trouble of over competition. Currently, the number of Chinese mainland massive diary industries is more than 700. And their product technology is highly homogenization. So they are independent and encounter predicament of price war. The notorious melamine incident is the inevitable outcome of vicious competition and effective supervision shortage.

It's useful to build a gaming model to reveal the depths of melamine event.

Gamers: diary enterprise A and B, homogeneity of their products, price elasticity of demand is more than 1; price is the critical factor of the purchase.

Payoff function: same price, then same profit. If A cuts its price and B maintain its original price, then A would gain more profit. If A and B cuts its price at same extent, they would gain the same profit but lower.

Excessive competition of China diary results in prisoners' dilemma of price, promotion and advertisement. If the supervision of product quality is ineffective, the competition based on rational individual would erode the cost, and "Melamine Event" would be inevitable.

\section{The change of China Diary's competition environment}

After "Melamine Event", diary's environment of competition has changed. First, standardization of China diary's competition environment achieved remarkable results. Government and relevant enterprises took an active action to eliminate the harmful effects. The authorities have introduced a range of plans to rectify the milk stations and diary processing enterprises to promote the level of quality and supervise, such as quality and safety of dairy products Regulatory Ordinance, diary industry rectifying and revitalization program planning, food safety law and so on.

Secondly, consumer buying behavior is more mature and rational. Quality and safety have become the chiefly factor affecting the buying of diary products. The milk source, quality and quality guarantee period have already exceeded brand and advertisement. 
Finally, the competition between well-known brand and second, third line brand became fierce. After "Melamine Event", Sanlu Group go bankrupt, and some well-known diary brand suffer great losses. The market share they lost causes more competition. Some diary enterprises with good reputation increase the marketing investment to expend nationwide and enter the leading echelon, for example: Wanda Shan, Feihe and so on. The sales volume of some diary enterprises whose product didn't contained melamine grows by $30 \%-50 \%$. Some regional brands gain greater development opportunity.

\section{Gaming of strategy —}

The internal per-capita consumption of milk is only $7.2 \mathrm{~kg}$, and less than $8 \%$ of global average. Agree inside course of study think, domestic diary market will be the largest in the following 10 years. After Melamine Event, we realize industry essence was ignored, the defect of product convergence, and the opportunity of industry rectification.

According to Peter Drucker, the social problem could be transformed into enterprises developing opportunity by the solving social problem rather than new technology, new product and new service. Diary enterprises must learn from mistakes and adjust competition strategy to get a long-term positive development.

\subsection{Industry essence and construction of stable and normative milk base}

Designing and executing strategy based on industry essence is the key for enterprises' success. Milk and powdered milk have become daily necessities and fast-moving consumer goods of many families. As nutritious foods Diary products' quality safety is industry essence and base of consumer confidence resumption. According to information of diary association, the cow population is $6,000,000$. According to the objective laws, the annual growth rate is $10 \%$. But the annual growth rate of diary industry is $30 \%$. So it is certain that milk scarcity would be the bottleneck of the industry development.

Form industry chain competition perspective, melamine event has exposed the defect of raw milk supply chain. A mismatch between milk source and processing industry leads to no guarantee of raw milk's quality. The key to improving the quality of raw milk is developing large-scale dairy farms. Most of enterprises run under their capacity as a result of milk resource restrict. So, diary industry competition has turned into the upstream resource competition. Steady and standard milk base become the key of competition.

To the tightness of combination of supply chain and enterprise, milk source organization pattern contains enterprise + farmer and enterprise + large-scale pasture. Currently the former is numerous. The lax pattern ship couldn't ensure the quality of raw milk, and its ability of resisting risk is worse. The latter takes active measures to promote collective, large-scale and scientific raising. The enterprises could have the whole productive process under control and could guarantee the quality of product. The milk source is the critical factor of competitiveness. So, the diary enterprises build more and more standard pastures even the investment is huge and the investment cycle is long.

Currently, the quantity of large-scale pastures is limited and couldn't meet the demand of raw milk supply. So, the diary enterprises should seek advanced management pattern of mild source, for example: "cow cooperative society" of Yili Group, organizes diary farmers, government department and milk station to resist risk. Enterprises connect directly with the scattered diary farmers to unify the milk collection, quality inspection. The administration cost is down, and the raw milk supply is steady and high-quality. This pattern proves the milk farmers' ability of risk-resisting, and accords with realistic condition of China.

\subsection{No differentiation competitive strategy}

Because of actual diary industry demand and freely diffusible industry technology, the difference between enterprises' products is small. Concentration, mouth fell, taste and supplement could be adjusted easily. Enterprises couldn't stay competitive by unique product characters for long term. The no differentiation competition is mainly in product homogeneity market, especially liquid milk market. Usually, the competitive strategy in no differentiation market is brand competition. But, after melamine event, the brand loyalty is not tall and couldn't effectively influence the consumer buying decision. In this case, the traditional competition factors become the main competition model.

\subsubsection{Concept competition}

Diary industry concept competition is divided into high-end and low-end. Low-end concept is expressed in some product stunt, for example, reconstituted milk, pure and fresh milk, thick milk, calcium milk and so on. High-end concept is reflected in product positioning appeal point, for example, "nature pasture" always is the appeal point every brand battles for, because the milk source could server as a foil to quality. 


\subsubsection{Talent competition}

At present, many young men with few working experience rise to important positions. Diary enterprises are faced with lack of talent. Superior talent resource is important for the comprehensive competitive power. Menniu is the model in talent resource. It has only a 3 years history, but most of its senior management has a working experience above 10 years. The talent resource is more important than capital.

\subsubsection{Price competition}

Price is a common competition method. In liquid milk market, many brands with lower price derived form size effect have competitive advantage. On Guangdong market, Yili group and Menniu group drive down price of extraordinary high temperature milk, Guangmin group grabs market share of fresh milk with low price.

\subsection{Differentiation competition strategy}

Chinese diary market is still in the demand- driven stage. Rural-urban difference, regional disparity and demand disparity provide the diary enterprises' differentiation competition strategy with abundant scope. The differentiation competition strategy is the medium-sized and small enterprises' best choice.

\subsubsection{Product differentiation}

The key to product differentiation is market segment. The enterprises must find the unsatisfied demand and fill the market space. The diary products have gradually become daily necessities rather than luxury. Take liquid milk as example. According to a survey, the infant demand accounts for $19 \%$ of the whole consumption, and old man over 60 years accounts for $28 \%$. People of all professionals are part of liquid milk consumption group. Difference of milk demand is very notable, and the diary enterprises could get differentiation advantage. As a temporary competition strategy, the product differentiation could help enterprises enter an emerging market, and get advantage. Sanyuan group cooperates with Jiaoda LP to compete against Guangmin Group with its temporary leading product.

\subsubsection{Channels expanding}

Channels expanding include three aspects. Expanding mail body is expanding into restaurants and taverns based on the exiting channels. The second is operational pattern expanding. Based on traditional wholesale and tail, the enterprises build the direct selling model to delivery the milk to door and order online. The third is channels expanding in depth and breath. The diary consumption and supply have been focused on urban market and the rural market has been neglected. The rural market's potential consumption is huge. During developing in rural market, the product form is important for product image of high quality and lower price, for example, high-capacity package, lower price, and longer quality guarantee period. In addition, it is useful to use the local selling resources to form an overlay area selling network.

\subsubsection{Promotion support}

Diary consumption is always impulse buying. The package, advertisement, price, display and shopping guide could effect the buying decision. But, the consumer wouldn't buy the same brand without combination of these elements. The consumer loyalty is related with the brand and product value. So the consumption transition would occur when the consumers realize some brand is material benefit. The diary enterprises must choose proper promotion pattern and pay attention to communication with consumers, because of consumer environment change and prudent buying.

When setting promotion pattern, enterprises should give consideration to consumer mental remedy after melamine event. They should pay attention to the consumers' experience and realize it is more important to make consumer experience the healthy and fashionable lifestyle advocated by the product than the taste, function and service. Then, the enterprises could enter the consumers' inner space, and affect the buying behavior.

\section{References}

Bo, Jianxin. (2009). Fingerprint of Chinese Diary Competition. Diary product and Human. 2. 56-59.

Feng, Chunmei. (2009). The Reason of Failure in Repair Diary Industry Brand. Market Observer. 1. 93-94.

Guo, Efeng. (2007). Focus of Chinese Diary Market Competition. Guangdong Diary Production. 2, 17-19.

Hou, Junwei. (2009). Strategy of Chinese Diary Industry. China Small \& Medium Enterprises. 2, 20-23.

Wang, yanxia and Li, Jinfei. (2009). Chinese Diary Industry Developing Strategy Analysis based on Pottsmodel. Jiangsu Commercial Forum.11, 122-124. 